\title{
Los rostros políticos de los evangélicos en la Argentina reciente
}

Recibido: 15 de julio 2018 Revisado: 17 de agosto 2018 Aprobado: 4 de agosto 2018

Marcos Carbonelli Argentino. Doctor en Ciencias Sociales por la Universidad de Buenos Aires, Magíster en

Ciencia Política por la Universidad de San Martín y Licenciado en Ciencia Política por la Universidad de Buenos Aires. Investigador asistente del Consejo Nacional de Investigaciones Científicas y Técnicas. Docente en la carrera de Ciencia Política y en la Maestría en investigación social de la Facultad de Ciencias Sociales (UBA). Docente regular en el Instituto de Ciencias Sociales de la

Universidad Nacional Arturo Jauretche. Trabaja temas de religión, política y metodologías de investigación sobre los que ha dictado cursos y publicado artículos, capítulos y libros, en español y en portugués.

Correo electrónico: m_a.carbonelli@yahoo.com.ar
Resumen: En este artículo analizamos los nuevos rostros políticos de los evangélicos en la Argentina reciente, haciendo foco en sus intervenciones en dos controversias públicas: la extensión de derechos sexuales y reproductivos y el proyecto de ley de cultos. Los argumentos están respaldados en la investigación cualitativa que sustentó nuestra tesis doctoral y en el diálogo con los principales antecedentes del campo. Mostraremos que la divergencia profunda en los posicionamientos evangélicos evidenció el quiebre de su constitución como movimiento social, al mismo tiempo que su creciente legitimación sociopolítica como minoría religiosa activa en el espacio público. También, identificaremos las múltiples alianzas entre actores evangélicos y católicos como una de las reconfiguraciones fundamentales en el campo político religioso argentino desde la recuperación democrática.

Palabras clave: Evangélicos; Argentina; política

\section{The Political Faces of Evangelicals in Recent Argentina}

Abstract: In this article we analyze the new political faces of evangelicals in recent Argentina focusing on their interventions in two public controversies: the extension of sexual and reproductive rights and the draft law of cults. Backed by the qualitative research that supported our doctoral thesis and in dialogue with the main background of the field, we will show that the deep divergence in the evangelical positions evidenced the breaking of its constitution as a social movement at the same time as its growing socio-political legitimation as an active religious minority in the public space. We will also identify the multiple alliances between evangelical and Catholic actors as one of the most important reconfigurations in the Argentine religious political field since the democratic recovery.

Key words: Evangelical; Argentina; politics 


\section{Introducción}

En las últimas décadas, uno de los fenómenos más analizados y debatidos en el campo de la sociología de la religión latinoamericana es la emergencia y el desarrollo demográfico del sector evangélico. Las razones de la atención concentrada en este grupo religioso radicaron, por una parte, en que su crecimiento (en alza desde la década del ochenta hasta nuestros días) se realizó a expensas de y en disputa con el catolicismo. Por el otro lado, despertó interés científico la vocación política de este grupo religioso, puesta de manifiesto en el armado de partidos confesionales, en los cuales la identidad cristiana se conjugaba directamente en la arena partidaria y se respaldaba en el voto comunitario.

Argentina no fue la excepción a esta tendencia y, de manera conjunta con la consolidación del sistema científico nacional, en la década del noventa, surgió una camada de estudios que abordaron la novedad evangélica y sus derivaciones políticas. Uno de los consensos más extendidos en este punto se circunscribió al fracaso evangélico en el campo partidario nacional: en el periodo de 1983 a 2011 ninguna fuerza o actor que apelara a la identidad cristiana pudo ganar elecciones. Este dato, constatado elección tras elección, además de singularizar al caso argentino dentro del contexto latinoamericano, incentivó a los investigadores locales a formularse nuevas preguntas: si los evangélicos no tenían éxito en las urnas ¿significaba que renunciaban a la proyección política? ¿Dónde buscar la politicidad evangélica?

Los interrogantes se saldaron con las movilizaciones que dirigentes de este espacio religioso protagonizaron en la década del noventa para frenar el avance de un marco legal restrictivo a sus intereses y derechos. Los evangélicos de diferentes denominaciones apartaron sus históricas diferencias y peticionaron juntos ante las autoridades; hecho que, desde la óptica de algunos investigadores, resultó sintomático de su constitución como un movimiento social.

El presente estudio procura continuar la reflexión sobre la politicidad evangélica en Argentina, haciendo foco en sus intervenciones en el nuevo milenio; en particular, en dos controversias públicas: la extensión de derechos sexuales y reproductivos y el proyecto de ley de cultos. Los argumentos están respaldados en la investigación cualitativa que sustentó nuestra tesis doctoral y en diálogo con los principales antecedentes del campo. Mostraremos que la divergencia profunda en los posicionamientos evangélicos durante estos debates evidenció, tan solo una década más tarde, el quiebre de su constitución como movimiento social, al mismo tiempo que su creciente legitimación sociopolítica como minoría religiosa activa en el espacio público. También, daremos cuenta de las múltiples alianzas que se dieron cita entre actores evangé- 
licos y católicos en el recorte temporal indicado y que anticipan una de las reconfiguraciones más importantes en el campo político religioso argentino desde la recuperación democrática.

El plan de nuestro texto será el siguiente. En el primer apartado, haremos una síntesis de la trayectoria política de los evangélicos como minoría en Argentina, teniendo en cuenta que la frecuente simbiosis histórica entre identidad católica e identidad nacional se constituyó en un obstáculo frecuente para su proyección. A posteriori, daremos cuenta de las movilizaciones evangélicas en el espacio público contra la ley de cultos y cómo esta acción colectiva sirvió de base de su composición como un colectivo unificado. Estos dos primeros apartados se sustentan metodológicamente en un análisis crítico de los principales antecedentes en la materia; en particular, de trabajos históricos, sociológicos y antropológicos que constituyen los cimientos del campo de indagaciones sobre el fenómeno evangélico en Argentina.

El tercer apartado, en cambio, se nutre del diálogo entre los hallazgos de nuestra tesis doctoral ${ }^{1}$ y una camada de estudios recientes, enfocados en el análisis de las intervenciones de agencias religiosas en controversias públicas a partir de la primera década del dos mil. En dicha sección, presentaremos secuencialmente los posicionamientos evangélicos en las controversias sobre la extensión de derechos sexuales y reproductivos y ley de cultos, y su impacto en la configuración de alianzas tanto internas como externas al mundo evangélico. Cerraremos nuestro estudio con la presentación de tres tesis; las dos primeras referidas a los cambios registrados en la politicidad evangé-
lica y la tercera vinculada con las transformaciones generales en la trama político-religiosa en Argentina desde la recuperación democrática.

1. Se trata de investigación empírica, de índole cualitativa, que indagó la proyección partidaria evangélica en la primera década del dos mil y sus conexiones con otras formas de producción política, también evangélicas. Se sustentó en treinta entrevistas en profundidad realizadas a líderes y candidatos evangélicos, análisis de fuentes secundarias y coberturas etnográficas de eventos políticos.

\section{Puntos de partida: la condición minoritaria en un país "católico"}

Toda aproximación sociológica hacia la participación política evangélica en Argentina debe partir de su condición de minoría religiosa, condición que, en términos históricos, moldea mas no determina sus expresiones políticas.

El arribo de grupos evangélicos a Argentina se remonta a las primeras décadas del siglo XIX, cuando la joven república intentaba mantener lazos sólidos con las potencias europeas y, en ese espíritu, concedió libertades y garantías a ciudadanos ingleses que transitaban el territorio argentino con fines comerciales y que deseaban practicar libremente su culto. El temprano tratado comercial de 1825 resultó un exponente de esta apertura religiosa e intención de congraciarse con la idiosincrasia cultural y religiosa de otros países (Di Stéfano y Zanatta 2000).

Bajo ese marco, a lo largo del siglo XIX, llegaron inmigrantes que, en el territorio nacional, formaron iglesias cristianas no católicas. Según un esquema consensuado entre los especialistas (cfr. Marostica 1997, 17-37; Wynarczyk 
2009), el espacio evangélico argentino se conformó a partir de tres corrientes u "olas" inmigratorias evangélicas.

La primera corresponde a las iglesias "históricas" (metodistas, valdenses, luteranos, anglicanos, entre otros) en la primera mitad del siglo XIX. Hacia 1880, llegaron las corrientes evangelicales, caracterizadas por una fuerte orientación misionera. Alrededor de 1910, se insertaron las primeras misiones pentecostales. Para Wynarczyk, Semán y de Majo (1995), este esquema se complementará más tarde con una cuarta corriente: el neopentecostalismo, acentuado por rasgos constitutivos del pentecostalismo clásico, mixturados con elementos inherentes a la religiosidad popular.

La situación política de esas comunidades cambió rotundamente a partir de las primeras décadas del siglo XX cuando la Iglesia católica promovió un esquema cultural basado en la simbiosis entre identidad católica e identidad nacional. En dicho patrón encontró receptividad las clases dirigentes de aquellos años, especialmente preocupadas por la heterogeneización del tejido social, que se había transformado rotundamente tras el masivo ingreso de inmigrantes entre 1870 y 1930.

La fusión entre identidad católica e identidad nacional se constituyó en una barrera que inhibió las expresiones religiosas en el espacio político, e inclusive fue el motor para acciones de hostigamiento, como las que se perpetraron en la década del treinta, en medio de la efervescencia del integralismo católico. Allí se propició una asociación entre otredad religiosa e invasión cultural: tanto la comunidad judía como los grupos evangélicos fueron acusados por grupos extremistas, así como por dirigentes políticos y eclesiásticos de contaminar la idiosincrasia nacional con ideas perturbadoras, como el marxismo o el liberalismo.

Cabe destacar que las persecuciones a la diversidad religiosa fueron resistidas por las comunidades religiosas evangélicas, a partir de liderazgos prominentes como el pastor William Morris (Seiguer 2015), que se aliaron con las figuras políticas disidentes para defender el derecho a la libertad religiosa y romper la asociación entre identidad nacional e identidad religiosa. Sin embargo, se trató de acciones limitadas y con poco margen, dado que buena parte de la historia política argentina en el siglo estuvo marcada por las interrupciones democráticas, y los gobiernos militares fueron, particularmente, receptivos a la asociación entre identidad católica y nacional.

Como menciona Mallimaci (2015), el proceso de militarización de la sociedad argentina coincidió y se retroalimentó con el de catolización: los diferentes Gobiernos militares encontraron en la apelación a la identidad católica una justificación para combatir y perseguir los focos revolucionarios, al mismo tiempo que la institución católica se apoyó en los militares para expandir tanto su estructura material (en términos de diócesis, capellanías e instituciones educativas) como su presencia simbólica en espacios y rituales públicos.

La disidencia religiosa pudo expresarse solo cuando existieron rupturas entre la dirigencia política y religiosa. Por ejemplo, el caso del conflicto que mantuvo Perón con la Iglesia católica durante su segunda presidencia (Caimari 
1995) y que propició su acercamiento a otras formas religiosas disidentes, como los espiristas, la escuela científico Basilio y el propio pentecostalismo, con la visita del pastor Hicks (Bianchi 2004).

En la década del sesenta, nuevamente bajo el régimen dictatorial, la persecución a las expresiones religiosas no católicas se redobló con la restauración del Fichero Nacional de Cultos no Católicos, un dispositivo jurídico cuya finalidad expresa era "controlar" todas las creencias no católicas (Catoggio 2008). Para aquellos años, la morfología del espacio evangélico en Argentina había cambiado sustantivamente.

Si en los inicios del siglo XX en el mundo evangélico persistía una identificación entre lo religioso y lo nacional/étnico bajo la idea de las iglesias como refugio de la etnicidad (Bianchi 2004), a partir de la década del treinta, las nuevas generaciones de evangélicos ya se consideraban ciudadanos argentinos y reclamaban sus derechos no solo a una libertad de culto nominal o en un régimen de tolerancia como el que existía hasta ese momento, sino en la igualdad plena en el ejercicio de la fe. Entre sus anhelos, se encontraba la pretensión de una sociedad perfectamente plural, pero para ello, requerían de una regulación estatal ecuánime; un hecho imposible mientras persistiera una definición particular del hecho religioso en Argentina, en el cual lo católico estaba anudado en el plano identitario a "lo argentino", y dicha asociación fuera fomentada y vigilada por el poder coercitivo militar.

Pese a esas dificultades, el contexto de hostigamiento no significó que las comunidades evangélicas se refugiaran intramuros. En este sentido, Bianchi (2004) plantea que durante la restauración de los tiempos persecutorios el espacio evangélico se dividió. Mientras las iglesias herederas de la primera reforma y asentadas en la Argentina en la primera migración (metodistas, valdenses, luteranos, evangélica del Río de la Plata, entre otras) se mostraron afinidades con el "evangelio social" y con el desarrollo de una pastoral cercana a la teología de la liberación, un segundo grupo (los evangelicales y pentecostales) se afilió a la corriente fundamentalista que sobrevino en las comunidades norteamericanas después de la Segunda Guerra, fortalecida a posteriori con la conformación de la Nueva Derecha Cristiana.

La dictadura militar de 1976 acentuó más esas diferencias en la medida en que el primer grupo se alió al sector progresista católico para conformar, en 1975, la Asamblea Permanente por los Derechos Humanos (APDH) y, en 1976, el Movimiento Ecuménico por los Derechos Humanos (MEDH); mientras que el segundo respaldó silenciosamente el golpe de estado (por considerarlo una medida oportuna y necesaria para frenar el avance del comunismo), o bien optó por recluirse bajo lo que Marostica denomina el paradigma misionero: una modalidad de organización eclesial de carácter cerrado, que fomentó la preservación de la identidad denominacional, el aislamiento social y el apoliticismo como dogma (1997, 247).

Wynarczyk (2009, 53-63) considera que estas diferenciaciones respondieron a matrices teológicas y, en razón de ello, llamó al primer grupo el polo histórico liberacionista y, al segundo, el polo conservador bíblico. El primero fundó 
sus posicionamientos públicos en una hermenéutica-histórica de la Biblia, en diálogo con las ciencias sociales y con una fuerte preocupación pastoral por la cuestión social, mientras que las iglesias pertenecientes al polo conservador bíblico se ajustaron a una lectura fundamentalista de los textos sagrados, que redundó en posicionamientos ortodoxos en cuestiones vinculadas a la moral sexual y al compromiso político. Este polo conservador bíblico se conformó por iglesias evangélicas, pentecostales y neopentecostales, y constituyen el grupo mayoritario al interior del espacio evangélico, que se nucleó en la Alianza Cristiana de Iglesias Evangélicos de la República Argentina (mayoritariamente, aunque no solo, pentecostal) y en la Federación Confraternidad Evangélica Pentecostal (FeCEP). Por su parte, las iglesias del primer polo confluyeron en la Federación Argentina de Iglesias Evangélicas (FAIE).

\section{Los evangélicos tras la recuperación democrática: movilización por la ley de cultos y conquista del espacio público}

La recuperación democrática en 1983 habilitó un nuevo escenario para las confesiones religiosas. Mientras la Iglesia católica revisaba sus relaciones con el poder político y con la sociedad argentina (Esquivel 2004), la libertad religiosa se reafirmó legalmente y, con ella, las acciones proselitistas de la disidencia religiosa en el espacio público. Por primera vez en la historia, los evangélicos contaron con un escenario favorable para intentar la expansión demográfica de sus iglesias a mediano y a largo plazo.

Tal como subrayan los trabajos Marostica (1997) y Wynarczyk (2009), este proceso también se benefició por un recambio generacional: los pastores más conservadores en sus prácticas y más celosos de la conservación de la identidad denominacional fueron sucedidos por una nueva camada de líderes que apostó a una renovación en la organización eclesial. Concretamente, innovaron en el aumento de las prácticas proselitistas en el espacio público, en el uso de los medios de comunicación y en el diálogo interdenominacional, con la consiguiente mayor circulación de recursos litúrgicos entre las diferentes iglesias; particularmente, desde el sector pentecostal hacia el resto de las comunidades, fenómeno que Wynarczyk, Semán y de Majo (1995) denominaron la pentecostalización del mundo evangélico.

Cabe destacar que este crecimiento de las denominaciones evangélicas, en específico la pentecostal, se hizo a expensas de las filas católicas. La explicación más convincente acerca de este cambio en el paisaje religioso argentino fue elaborada por Semán (2000) en uno de los estudios pioneros sobre el pentecostalismo. Según este autor, el pentecostalismo creció en los sectores populares en la Argentina durante la década del noventa porque se trató de la forma religiosa que, de manera más acabada, pudo desarrollar un discurso y una práctica pastoral capaz de tematizar y de acompañar las situaciones de descenso social que experimentaban, de manera vertiginosa, extensos sectores de las clases medias y populares de la Argentina (Auyero 
2001; Merklen 2005). Mientras que el catolicismo se encontraba sumido en un proceso de racionalización y de burocratización de su oferta de bienes de salvación, el pentecostalismo de raigambre local establecía un exitoso puente con el carácter cosmológico, holista y relacional propio de la religiosidad popular en Argentina (Semán 2006).

Dicho ciclo de apertura hacia el espacio público también estimuló el interés por la participación política en los evangélicos. Por generaciones, habían sido socializados bajo el pensamiento de que la política era un ámbito pecaminoso, capaz de corromper inclusive a los bienintencionados (cfr. Wynarczyk 2009 y Marostica 1997). Bajo esta cosmovisión, el creyente no debía inmiscuirse en ese tipo de ámbitos, sino consagrarse a la lucha espiritual y al acceso a los bienes de salvación.

Las nuevas camadas de pastores cuestionaron esas enseñanzas y creyeron que el contexto democrático era el escenario propicio para que los evangélicos reivindicaran su lugar como legítimos participantes de la esfera pública argentina. De forma paralela, la política pasó a ser conceptualizada como ámbito de misión: los evangélicos se consideraban a sí mismos como agentes redentores del mundo de la política, capaces de quebrar las lógicas instrumentales, el circuito de prebendas y el ansia del poder; y de suplantar estos elementos por dinámicas de actuación informadas por el compromiso, la honestidad y la búsqueda del bien común.

A su tiempo, esta proyección se veía alimentada por un efecto imitativo: en otras regiones de Latinoamérica, como Brasil (Silveira Campos 2005; Campos Machado 2006), las incursiones evangélicas en el mundo de la política comenzaban a rendir sus frutos y sembraban en pastores y líderes evangélicos argentinos un imaginario de éxito potencial. Sin embargo, en el caso argentino, las incursiones evangélicas en el ámbito partidario fueron infructuosas.

Tras reuniones preliminares en la década del ochenta, en 1993, un grupo de pastores pentecostales fundó, en la zona del Gran Buenos Aires, el Movimiento Cristiano Independiente, un partido confesional que se orientaba a reivindicar la identidad evangélica en el espacio partidario. Este partido tambien tuvo su expresión en la provincia de Córdoba y se denominó Movimiento Cristiano. La propuesta electoral de tales agrupaciones era una mixtura entre reivindicaciones y demandas propias del grupo religioso y la idea de redención de la política.

Estos grupos compitieron con magros resultados en las elecciones legislativas de 1994 y, más tarde, en la convocatoria por la conformación de la convencional constituyente. Tras las sucesivas derrotas en los comicios electorales de 1993, 1994 y 1995, un desprendimiento del MCl fundó el Movimiento Reformador (MR), el cual abandonó la idea de un partido confesional y apostó por una política de alianzas, comportándose como un espacio evangélico dentro de estructuras políticas "seculares".

En tal etapa, sus miembros integraron primero el Frente para un País Solidario, después, la Democracia Cristiana y, por último, el Polo Social, dirigido por 
Luis Farinello (Wynarczyk 2010, 325). Se trataban de espacios integrados con cuadros peronistas disidentes al Gobierno menemista, con los que los pentecostales mantenían valores en común, como el discurso anticorrupción y la búsqueda de la justicia social. Tras el cierre de la experiencia del Polo Social, los evangélicos se retiraron de la arena partidaria.

Según la literatura especializada, el fracaso de los partidos confesionales radica en una explicación doble. En primer término, cuando estos grupos intentaron conquistar adhesiones en las propias comunidades religiosas, fueron advertidos por la mayoría de los pastores, quienes se negaban a la politización de la grey (Wynarczyk 2006, 27-30). Tampoco tenían apoyo de las federaciones, porque sus dirigentes conceptualizaron la propuesta partidaria como un elemento que propiciaba la desarticulación y el antagonismo antes que la unidad al interior del campo evangélico.

En segundo lugar, la suerte política de las experiencias confesionales se sustentó (equivocadamente) en la existencia de un "voto evangélico". El escaso caudal electoral obtenido en las sucesivas presentaciones afirmó, por el contrario, la densidad histórica de las identidades políticas tradicionales en Argentina (Wynarczyk 2006, 29). En este sentido, Wynarczyk y Oro aseveran que "el voto de la mayoría de los evangélicos parece asociado a un habitus político construido fuera de las congregaciones (...) la mayoría de los pentecostales tienen al voto peronista" (2012, 29). Siguiendo a Freston (2001), para Wynarczyk (2010, 205-206), el fracaso de las participaciones evangélicas en el campo partidario responde a las características del sistema partidario argentino, centrado en esa década en un bipartidismo cohesivo, fundamentado a su vez en la división de clases sociales, Sin embargo, el paso fallido de los partidos confesionales no monopolizó la expresión evangélica en política. Por el contrario, en los años noventa tuvo lugar una segunda intervención, emplazada en la movilización en el espacio público y estrictamente vinculada a una reivindicación como minoría religiosa.

El crecimiento y el aumento consecuente de la visibilidad de los evangélicos a los que aludíamos en párrafos precedentes originó reacciones en el establishment político-religioso. En un documento publicado en 1986 (De Risio 2018), el Episcopado Católico denunció la infiltración de diversas sectas en territorio nacional, ajenas y dañinas de la idiosincrasia religiosa nacional. Sectores intelectuales y funcionarios se hicieron eco de estas preocupaciones e iniciaron una campaña antisectas, que tuvo lugar entre los años 1986 y 1993 (Frigerio y Wynarczyk 2008, Marostica 2000). Mediante campañas publicitarias y una serie de participaciones en espacios televisivos y radiales, estos sectores etiquetaron a los evangélicos (entre otros cultos) como sectas.

Siguiendo la perspectiva de Becker (2010), el etiquetado constituye una práctica social orientada a designar las fronteras entre lo normal y lo marginal (outsider). En el caso que estamos analizando, se trató de marcar la distancia existente entre los evangélicos (entendidos como sujeto colectivo) y un orden moral estructurado bajo la lógica de la preeminencia católica y donde toda disidencia era alcanzada por un halo de sospecha. 
En 1993, estos sectores cercanos al integralismo católico intentaron plasmar sus cosmovisiones acerca de la normalidad religiosa en una nueva legislación de cultos, de carácter restrictivo, orientada a cercenar las actividades de los evangélicos, entre otros cultos.

Para Wynarczyk (2009), estas acciones activaron una respuesta clave en el mundo evangélico. Sintiéndose amenazadas, las federaciones evangélicas, la Alianza Cristiana de Iglesias Evangélicas de la República Argentina (ACIERA), la Federación Argentina de Iglesias Evangélicas (FAIE) y la Federación Confederación Evangélica Pentecostal (FeCEP) encabezaron las acciones de movilización y protesta. A los fines de coordinar sus acciones y en un gesto inédito de unidad en el mundo evangélico, las entidades mencionadas confluyeron en la organización del Consejo Nacional Cristiano Evangélico (CNCE).

A posteriori, desdoblaron sus estrategias defensivas en varios frentes: por un lado, en la arena jurídica, a partir de la organización de reuniones y presentaciones formales ante los diferentes Gobiernos para gestionar un nuevo estatus jurídico que derogara los mecanismos de demarcación del campo religioso, originados en la última dictadura y que diera paso a un marco de mayor igualdad entre los diferentes cultos. Por el otro, en la organización de concentraciones públicas. En 1993, tuvo lugar la primera, frente al congreso nacional, donde seis mil creyentes, aproximadamente, se convocaron para repudiar la media sanción que el Senado nacional al proyecto restrictivo motorizado por sectores católicos integralistas.

El proyecto finalmente no prosperó, y los evangélicos pasaron a la ofensiva. El Obelisco se convertiría en el escenario donde las federaciones convocaron, en 1999 y en el 2001, a todas las denominaciones evangélicas a la manifestación pública, con el doble propósito de orar por la nación y sus gobernantes, y poner en escena el marco de desigualdad que estructura el campo religioso en Argentina. La demanda no alcanzó su cometido por el veto final del episcopado y por la crisis política, económica y social de los años 20012002, que reasignó prioridades legislativas y postergó debates en pos de urgencias, como la contención a los sectores socialmente más vulnerables.

Tanto para Marostica $(1994,1997)$ como para Wynarczyk (2009), la lucha contra la estigmatización en el contexto democrático marcó un punto de inflexión en la historia política de los evangélicos, en la medida en que dio lugar a su conversión en movimiento social. Las campañas pastorales de la década del ochenta prepararon el terreno porque dotaron de lenguajes, liturgias y modelos pastorales comunes a un colectivo hasta ese momento fragmentado. También, la actividad de evangelización motivó la generación de recursos y de nuevas herramientas, como la adquisición de medios masivos de comunicación y el desarrollo de cierta experiencia en la ocupación de lo público. Pero el paso decisivo resultó una movilización del conjunto "de la Iglesia" en contra de una iniciativa legislativa claramente contraria a sus intereses y a la continuidad de su expansión. 
En la construcción del movimiento, Marostica (1997) y Wynarczyk (2009) coinciden en la importancia crucial de los liderazgos y su tarea clave en la construcción de marcos interpretativos convincentes para lograr movilizaciones efectivas en el espacio público. Si en los años ochenta ganó adhesiones, la idea de que la Argentina era una tierra visitada por el Espíritu Santo y que los evangélicos eran quienes agenciaban esa visita, en los años noventa, cobró potencia política el marco que señalaba el peso de una amenaza de persecución legal, pergeñada por un complot católico (Marostica 2000).

\section{El nuevo milenio. Intervenciones encontradas y fragmentación comunitaria}

Si se compara con el punto de partida que significó la restauración democrática, la situación de los evangélicos en Argentina, al iniciar el nuevo milenio, no podía ser más auspiciosa: en noviembre de 2001, lograron una movilización masiva en el Obelisco donde reiteraron su reclamo de igualdad de cultos y oraron por la nación argentina; pero esta vez lo hicieron frente a las autoridades de la nación, contando, incluso, con la asistencia del entonces presidente, Fernando de la Rúa.

Un año más tarde, cuando la crisis económica, social y política del país arreciaba, los evangélicos fueron invitados, bajo la figura del CNCE, para integrar la Mesa ampliada del Diálogo Económico y Social y colaborar con el Poder Ejecutivo Nacional en el diseño de políticas de emergencia (Carbonelli, 2015a). En el plano simbólico, se trataban de gestos que rompían con la estigmatización oficial y oficiosa de la cual habían sido objetos durante gran parte de su historia. De minoría perseguida y asociada a una otredad peligrosa y distante del ser nacional, los evangélicos pasaron a ser un grupo religioso con acceso al espacio público, capaz de elevar peticiones consideradas legítimas, e incluso valorados por su acción social, al punto tal de ser incluidos dentro de un programa de políticas públicas.

En el periodo 2003-2010, este espacio religioso se fracturó. Su división respondió a posiciones divergentes en torno a dos controversias medulares: los debates sobre la extensión de derechos sexuales y reproductivos en Argentina y la discusión respecto a un nuevo proyecto de ley de cultos. Como veremos a continuación, en las participaciones evangélicas en estas discusiones, se produjo un importante reacomodo de alianzas y redefinición de antagonismos, que fracturaron la constitución del espacio como movimiento social; al mismo tiempo, reconfiguraron las relaciones de fuerzas del campo religioso en Argentina. 


\section{Las intervenciones en la esfera de los derechos sexuales y reproductivos}

En la primera década del dos mil, el ciclo de intervenciones públicas en estos tópicos se inició con la oposición de ACIERA a la promulgación de la Ley de Unión Civil en la Ciudad Autónoma de Buenos Aires en 2003 y a los proyectos de ley de Educación Sexual Escolar en 2004. Por primera vez, esta federación salía al cruce de una iniciativa política que no tocaba directamente sus intereses como minoría religiosa, sino que procuraba alterar un orden simbólico considerado primordial por la cosmovisión religiosa de esta organización. Nos referimos, puntualmente, a la heterosexualidad como patrón estructurante de la vinculación familiar y a la soberanía de los padres en lo que refiere a la educación de sus hijos.

El trabajo de Jones, Azparren y Polischuk (2010) reconstruye este posicionamiento pionero de ACIERA en estas controversias, sus argumentos y las reacciones que desató en otras denominaciones. La citada federación impugnó estos cambios legislativos mediante comunicados públicos y se apoyó en una combinación de argumentos. Por un lado, cuestionó el avance de la regulación estatal en la esfera íntima (la vida, la familia y el matrimonio) en virtud de la defensa de un orden considerado natural, sagrado; pero al mismo tiempo concordante con una tradición jurídica y cultural inamovible. Responsabilizaron a la ideología del género y a la comunidad gay LGBTI por esta avanzada. Por el otro, los dirigentes de ACIERA se presentaron públicamente como representantes excluyentes de la postura evangélica.

Estos pronunciamientos despertaron la reacción de dos iglesias del arco protestante histórico: la Iglesia Evangélica Luterana Unida (IELU) y la Iglesia Evangélica del Río de la Plata. En primer lugar, desautorizaron a la federación ACIERA en su intencionalidad de arrogarse la representacion del conjunto del campo evangélico. Al mismo tiempo y en sintonía con su trayectoria en el campo de los derechos humanos (Jones, Cunial y Quintáns 2014), se pronunciaron en favor de los grupos considerados marginalizados por el Estado; en este caso, la comunidad gay. Lo hicieron a partir del lenguaje y los recursos simbólicos del paradigma de los derechos humanos: más allá de las mayorías de opinión circunstanciales, para estas comunidades, los derechos de las personas (en aquella ocasión, a casarse bajo el reconocimiento y el amparo de la ley) resultaban inalienables. Pero también robustecieron su posicionamiento apelando a fundamentos bíblicos. En efecto: a los fines de mostrar el carácter endeble de los argumentos de sus adversarios, los pastores de la IELU y la IERP se apoyaron en relatos de las Sagradas Escrituras, en las cuales, en su perspectiva, quedaba claro cómo la voluntad divina apoyaba siempre a los oprimidos.

En definitiva, la controversia por la sanción de la Ley de Educación Sexual y de Unión Civil provocó la primera grieta en el espíritu de unidad que había predominado durante buena parte de la década del noventa y que había sido fundamental para frenar la legislación restrictiva que estigmatizaba a los evangélicos, asociándolos a una secta. Los desacuerdos inclusive malogra- 
2. Cabe aclarar que Hotton no alcanzó su puesto como diputada nacional por sus contactos y capitales en el espacio religioso, sino por el legado paterno y por su sólida carrera profesional en el mundo diplomático y del comercio exterior. ron la realización del tercer obelisco evangélico, que se había proyectado como una continuidad de sus antecesores exitosos, en la convocatoria de 1999 y 2001 (Jones, Azparren y Polischuk, 2010). Cuando los dirigentes de ACIERA quisieron incluir la condena a las nuevas reglamentaciones jurídicas en las proclamas del evento, las IELU y la IERP se negaron y anunciaron que no participarían. Temiendo una exacerbación aún más fuerte de los enfrentamientos y una escalada de deserciones, los organizadores terminaron suspendiéndolo.

Las querellas evangélicas se radicalizaron aún más durante el debate en torno al matrimonio igualitario, en 2010. Pero para entender en profundidad este proceso de confrontación, es preciso incluir un actor más: la diputada Cynthia Hotton. Su trayectoria fue descripta y analizada por el estudio de Carbonelli (2015a), en el cual se muestra cómo esta integrante de una de las familias mas tradicionales y conocidas del mundo evangélico, una vez electa diputada,comenzó a hacer de su identidad religiosa el eje de su proyección política. $^{2}$

Entre los años 2007 y 2011, su agenda como legisladora combinó apoyos al Partido Propuesta Republicana y al programa de la centro-derecha en el ámbito nacional, con una creciente atención a las necesidades y preocupaciones de la comunidad evangélica en Argentina. Fue clave su mediación ante autoridades del Gobierno de la ciudad de Buenos Aires y nacional para llevar a cabo el Festival Sí a la Vida, del predicador Luis Palau en el obelisco porteño en marzo de 2008 (Carbonelli y Mosqueira 2008). También, se opuso a la extensión del beneficio de la obra social a las parejas homosexuales y, junto al pastor Ale Gómez, coordinó un evento multitudinario de jóvenes que se manifestaron contra la despenalización del aborto, que los colectivos asociados a la agenda feminista y al kirchnerismo impulsaban en 2009 y 2010.

A inicios del 2010, comenzaron a circular proyectos de ley que procuraban promover el matrimonio legal y el derecho a la adopción para parejas del mismo sexo (Hiller 2011). Estas iniciativas no solo fueron discutidas en los ámbitos estrictamente parlamentarios (como las comisiones de tratamiento o el propio recinto). Asimismo, se desplegaron, siguiendo la conceptualización de Daniel Cefaï (2002), por diferentes arenas públicas: los medios de comunicación (en particular programas radiales y televisivos que invitaban a referentes de cada una de las posiciones para que debatieran en vivo) y la calle, con marchas o reuniones tendientes a visibilizar los consensos, los apoyos y los rechazos. El despliegue del debate en el espacio público duró seis meses hasta la sanción definitiva de la ley por la afirmativa y, durante este, Cynthia Hotton se posicionó públicamente como una de las referentes a ultranza del rechazo a esta iniciativa. Decidió jugar públicamente el rol propio de un emprendedor moral (Becker 2010): una persona que decide difundir públicamente un ideario de valores con un fuerte contenido normativo, de manera tal de marcar o denunciar la desviación a un orden social pretendido como correcto y al que es preciso defender.

En primer lugar, en el mes de abril, Hotton organizó, junto con la federación evangélica ACIERA, una asamblea frente al Congreso Nacional para mostrar 
el rechazo público a la ley. No se trató de una reunión exclusivamente evangélica, porque Hotton también hizo partícipe de ella a la diputada Liliana Negre de Alonso, reconocida católica y detractora del proyecto de matrimonio igualitario. La oposición al proyecto se fundaba en la articulación de argumentos de diferente raigambre: desde la apelación a la existencia de un orden moral, cuasi sacro y, por ende, situado por fuera y por encima de las contingencias políticas, hasta la justificación jurídica (el proyecto del matrimonio igualitario iba a contramano de pactos suscritos con anterioridad por el Estado argentino) pasando por argumentos científicos (la supuesta demostración psicológica acerca de la inestabilidad de las parejas homosexuales y sus secuelas en la crianza de sus hijos) y por la apelación a la existencia una mayoría moral, cuyos valores eran totalmente contrarios a la de las minorías intensas, promotoras de los nuevos derechos (Jones y Carbonelli 2012).

A la movilización de abril contra el matrimonio igualitario (convocada exclusivamente por actores evangélicos conservadores) le siguió otra en el mes de mayo, en el mismo escenario, pero que ya contaba con la presencia de actores católicos que compartían su preocupación y su ideario, y que se unieron bajo el lema: "Un mensaje de los niños: queremos mamá y papá" (De Risio 2018). Se estrechaba así una alianza interreligiosa inédita en el campo político argentino (Carbonelli, Felitti y Mosqueira 2011), de cuño conservador.

Por efecto especular, dicha unión provocó su reverso: una alianza interreligiosa progresista y favorable a la extensión de los Derechos Sexuales y Reproductivos. Esto último ocurrió porque la politización reactiva de los sectores conservadores religiosos, tanto católicos como evangélicos (Vaggione, 2005), volvió a apelar a la idea de la mayoría moral y a un discurso esencialista: en sus argumentos la identidad religiosa estaba anudada a la oposición al matrimonio igualitario, sin dejar lugar a la disidencia o al debate interno.

Este posicionamiento fue el que motivó que grupos de sacerdotes y de comunidades evangélicas del mundo protestante respaldaran el proceso de ley, también a su turno, apelando a una diversidad de razonamientos. Los derechos de las minorías conformaron un denominador común, pero también la referencia a pasajes bíblicos, interpretados en clave liberacionista. Como señalan Vaggione y Jones (2015), en el juego de argumentaciones y contrargumentaciones, la apelación al ideal normativo de la laicidad del Estado ocupó un lugar menor. Por el contrario, inclusive en los defensores del proyecto del matrimonio igualitario, el discurso religioso se transformó en un recurso frecuente, tanto por los actores pertenecientes a ese mundo como por no pocos legisladores. Cabe destacar que el movimiento LGBTI, estratégicamente, advirtió esta disidencia religiosa favorable a sus intenciones y organizó encuentros entre las partes interesadas, como la reunión que se realizó el 16 de junio en la Iglesia metodista de Flores (ciudad de Buenos Aires) bajo el nombre "La Fe dice sí a la igualdad" y que contó con la participación de referentes históricos del protestantismo (metodistas, luteranos, Iglesia evangélica del rio de la Plata) y laicos y sacerdotes católicos.

La votación final de ley que concedió la potestad de la adopción y del matrimonio legal a personas del mismo sexo tuvo lugar el 15 de julio de 2010. 
Mientras los senadores debatían en una extensa jornada que se prolongó hasta la madrugada, en la calle, los detractores y los promotores de la iniciativa organizaron una vigilia para manifestar sus voluntades e intereses. En el primer grupo volvieron a reunirse ACIERA, FeCEP, la diputada Hotton y grupos católicos, como Scouts y Acción Católica. Inclusive, la jerarquía católica movilizó a estudiantes de colegios parroquiales para mostrar la fuerza de la oposición al matrimonio igualitario en esa jornada. Jones y Cunial (2012) destacan que, en el despliegue de esta controversia religiosa, los evangélicos llevaron la delantera en cuanto a la movilización callejera y que dicha anticipación fue resaltada y valorada por los sectores católicos, los cuales hasta ese momento habían optado por estrategias de persuasión menos visibles, como el lobby y la presión mediática.

\section{El fallido intento de una nueva ley de cultos}

Las divergencias evangélicas descritas se acentuaron a la luz de un segundo debate, cronológicamente contiguo al del matrimonio igualitario. Nos referimos a las controversias desatadas por el proyecto de ley de cultos presentado por la diputada Cynthia Hotton en agosto de 2010.

En su reconstrucción del devenir de esta causa entre 2001 y 2010 , el estudio de Carbonelli y Jones (2015) señala que las federaciones evangélicas intentaron retomar el trabajo realizado en la década anterior en este campo e impulsar una ley definitiva. Existieron preproyectos, ronda de consultas que incluyeron a las tres federaciones evangélicas, al episcopado católico y a la Secretaría de Cultos.

Todas estas iniciativas resultaron infructuosas, sin siquiera alcanzar al recinto parlamentario. La excepción resultó el proyecto de la diputada Hotton que, a diferencia de todos sus antecesores, logró, en 2010, ser discutido en comisiones legislativas y obtener dictamen favorable. Postulaba el mantenimiento de la posición diferencial de la Iglesia católica en el campo religioso y la creación de la figura de la personería jurídica religiosa para todas aquellas otras confesiones que cumplieran con requisitos, tales como la acreditación de la presencia efectiva en el territorio argentino, un informe detallado de los principios y doctrinas religiosas y la identificación de autoridades administrativas. El reconocimiento estatal habilitaba prerrogativas como la exención de impuestos fiscales, la inembargabilidad e inejecutabilidad de los templos, lugares de culto y objetos sagrados y el libre acceso de sus ministros a las cárceles, hospitales, asilos y dependencias de las Fuerzas Armadas. Cabe destacar que el proyecto Hotton poseía una cláusula restrictiva donde marginaba de la nominación religiosa al estudio de la parapsicología, a la astrofísica, la astrología, las prácticas adivinatorias o mágicas, a las prácticas satánicas y a los cultos cuyos oficios religiosos incluyan actos de crueldad sobre animales, y también, estipulaba la posibilidad de castigar penalmente a quienes injuriaran públicamente a una autoridad religiosa.

En suma, la iniciativa legislativa de Hotton se proponía alterar, de modo parcial, las fronteras del campo religioso a partir de un modelo de estratificación 
tripartito. El catolicismo permanecería en un sitial de religión preferencial por el financiamiento estatal y por su prescindencia del reconocimiento del Registro de Cultos. Los credos, "reconocidos" por el poder público, obtendrían garantías para ampliar su actividad proselitista en diversos espacios públicos. Finalmente, el último nivel se reservaría a los cultos afroamericanos (umbanda, batuque, candomble) y a prácticas de curanderos y adivinadores, excluidos del reconocimiento estatal y posicionados por fuera del campo religioso legítimo. En las primeras rondas de consulta y debates, el proyecto Hotton tuvo el respaldo explícito de las federaciones ACIERA y FeCEP.

Pese a una primera etapa auspiciosa, el proyecto no llegó a debatirse en el recinto legislativo y perdió estado parlamentario. El desencadenante de su fracaso resultó en fuertes críticas que le propinaron sectores evangélicos, no solo del polo histórico, como la FAIE, sino también de iglesias pentecostales y megapentecostales, a saber: el pastor Guillermo Prein del Centro Cristiano Nueva Vida. Sus cuestionamientos hacían foco en que el proyecto Hotton abandonaba la causa de la igualdad religiosa (valor rector de la lucha evangélica de los años noventa) y legitimaba el rol arbitral del Estado al momento de reconstruir las fronteras de lo religioso (Carbonelli y Mosqueira 2012). En este esquema, los evangélicos pasaban así de culto perseguido a culto establecido. De etiquetados a etiquetadores.

Semanas más tarde, la organización CEPAS también criticaría fuertemente el proyecto y haría blanco en los avales y derechos que el proyecto Hotton otorgaba a las organizaciones de segundo grado (federaciones y confederaciones) por sobre las de primer grado. Esta crítica desnudaba un creciente malestar de consejos pastorales e iglesias barriales con el liderazgo de ACIERA (Carbonelli y Mosqueira 2012).

A diferencia de lo acaecido en la controversia sobre el matrimonio igualitario, el clivaje que organizó los enfrentamientos evangélicos no siguió los criterios clásicos de un polo conservador bíblico enfrentado a un polo histórico liberacionista. Se estructuró más bien a partir de una rivalidad intensa entre quienes bogaban por la institucionalización de un régimen de desigualdad y quienes lo rechazaron. Dicha rivalidad atravesó, fragmentó y diluyó los polos anteriormente mencionados, y puso en entredicho su vigencia como herramienta heurística para interpretar las fracturas políticas del mundo evangélico en la primera década del milenio.

\section{Conclusiones}

Nuestro examen sobre los principales litigios que envolvieron a los evangélicos en el primer milenio nos conduce al desglose de una primera tesis: pese a sus variadas intervenciones en el espacio público, los evangélicos no se consolidaron como movimiento social en la década del dos mil. Por el contrario, se dispersaron en un conglomerado de agencias y de posiciones en dis- 
puta, cuya legibilidad responde tanto a los parámetros clásicos, de orden teológico, como a nuevos clivajes. En primer lugar, este panorama se explica por la ausencia de marcos interpretativos y líderes consensuados en el espacio evangélico durante el período 2001-2010. Tanto la polémica por la intervención en los debates sobre derechos sexuales y reproductivos como la orquestada en torno al proyecto de ley de cultos mostraron interpretaciones disímiles y contrapuestas que convivieron, de manera conflictiva, en el mismo espacio religioso. En efecto: mientras algunos sectores interpretaron la primera década del milenio como el momento de desplegar un avance sustantivo sobre las esferas públicas para reposicionar definitivamente a los evangélicos como una religión establecida y, al mismo tiempo, frenar iniciativas que ponían en riesgo valores considerados vitales y adheridos a la identidad nacional (naturalizada como cristiana y pro vida); otros sectores eligieron acompañar la extensión de derechos sexuales y reproductivos, y cuestionar lógicas de empoderamiento en las cuales lo evangélico asumía de forma implícita, posiciones de privilegio y roles de control. En esta última línea, las disputas por la nominación del colectivo evangélico escenificaron criterios antagónicos en torno a cuál debía ser el rostro público de esta confesión religiosa. Por un lado, actores como la IELU o la IERP pretendían un rostro público cercano al ideario protestante tradicional, partidario de una separación total entre Estado y creencias religiosas, y de una nula injerencia de lo religioso en el ámbito político. Por el otro, las federaciones ACIERA, FECEP y actores cercanos a su propuesta pública, como la diputada Hotton, ensayaron una modalidad de religión pública "a la católica", en cuyos parámetros la acción estatal se subordina a la tutela de la cultura cristiana y sus instituciones guardianas.

En el mismo sentido, la década del dos mil resultó el tiempo de los liderazgos cuestionados antes que consolidados. Por un lado, existieron líderes que construyeron apuestas representativas, es decir, maniobras discursivas orientadas a posicionarse como representantes de la totalidad de los evangélicos en cada controversia o polémica en la cual participaban. Por el otro, liderazgos o autoridades que no ensayaron ningún tipo de apuesta representativa, pero que se encargaron de desautorizar las construidas por otras federaciones e iglesias. A diferencia de la década del noventa, cuando de manera circunstancial, las federaciones ACIERA, FAIE y FeCEP lograron representar al colectivo en la demanda por la igualdad, en la década del dos mil se puso en evidencia que el problema político de los evangélicos en Argentina es la unidad y la representación (cfr. Algranti 2010 y Semán 2013).

Inclusive si analizamos la situación evangélica a la luz de otras teorías sobre identidades colectivas, encontramos nuevas argumentaciones que respaldan nuestra oposición al tratamiento de esta minoría religiosa como movimiento social. Aboy Carles (2001) analiza la constitución de identidades colectivas a partir de la tríada antagonismo-tradición-representación. La definición de una otredad antagónica resulta vital para el trazado de las fronteras de la propia identidad con respecto al exterior. Dicha tarea no acontece en un "vacío de sentido", sino que se realiza en diálogo con un campo preexistente de rela- 
tos, tradiciones y pertenencias. La articulación de estas dos operaciones (definición del otro y recuperación/resignificación de tradiciones) tiene lugar en el momento de la representación. En tanto acción performativa y no mero reflejo, la representación juega un rol clave, porque propicia el cierre interior (provisorio) de la superficie identitaria, al mismo tiempo que se escenifica (también provisoriamente) el sujeto político en cuestión. Si retomamos estos tres vectores (antagonismo-tradición-representación) a la luz de las controversias analizadas, daremos cuenta, una vez más, de la imposibilidad de la construcción de una identidad colectiva evangélica en el periodo indicado.

Para sectores como ACIERA, FeCEP y la diputada Hotton, sus antagonistas durante la década del dos mil fueron, por un lado, las feministas, el colectivo LGBTI y los actores políticos cercanos a sus demandas. Por el otro, los umbandas, las diferentes formas de curandería y la parapsicología, es decir, todas aquellas formas religiosas consideradas ilegítimas acreedoras del reconocimiento estatal. Nótese que, para los actores mencionados, la jerarquía católica dejó de ser el adversario por antonomasia (como había sucedido en los años 1990) y pasó a ser un aliado incondicional en las disputas que libraron. En cambio, para las iglesias del protestantismo histórico aglomeradas, así como para algunos consejos pastorales e iglesias pentecostales de pequeño, mediano y gran tamaño, el oponente continuó prefigurado en un orden legal que mantenían privilegios y demarcaba jerarquías, tanto en el campo religioso como en el plano más general de los derechos sexuales y reproductivos. En el plano de las tradiciones también encontramos continuidades, rupturas y resignificaciones. Mientras las iglesias del arco protestante mantuvieron su histórica defensa de un modelo estatalista sin tutela religiosa, al que se plegaron líderes como Prein u organizaciones como CEPAS; ACIERA, FeCEP y un círculo importante de actores cercanos optaron por romper con la tradición protestante y ensayaron un formato de religión pública a la católica, como lo definimos más arriba. De manera consecuente, las diferencias en el terreno de los antagonismos y en el de la resignificación de tradiciones hizo imposible la constitución de una representación definida. Existieron apuestas representativas, como las de ACIERA o las de Hotton, pero fueron impugnadas ostensiblemente por quienes no compartieron sus maneras de construir el rostro público evangélico. En definitiva, del movimiento a la disputa (disputa por el rostro público evangélico) resulta ser la parábola trazada por el ciclo de politización de los evangélicos en la arena política argentina reciente. La distancia existente entre la posición de ACIERA y el modelo de intervención de la IELU o la IERP (por solo citar un ejemplo) visibiliza el hiato que tornó imposible la identidad común.

El desgarramiento de la condición movimentista nos conduce, no obstante, a una segunda tesis. La expresión de los diferentes rostros políticos evangélicos, aun en su litigio, ponen de manifiesto el creciente proceso de legitimación sociopolítica de los evangélicos. Dicho grupo religioso luchó con energía contra la estigmatización social de la cual fue objeto en los años noventa, y una vez rota la barrera del estigma, acrecentó su presencia pública gracias al reconocimiento que el poder político y el religioso hicieron de su crecimiento 
demográfico, de su capacidad de movilización en el espacio público y de su trabajo social entre los sectores menos favorecidos de la sociedad.

Profundicemos en este punto. El ciclo de intervenciones evangélicas en los debates sobre la extensión de derechos sexuales y reproductivos en la década del 2000 puso de manifiesto cómo la jerarquía católica, otrora adversaria y ente regulador de la definición social del hecho religioso en Argentina, reconoció el poder de movilización callejera y de persuasión pública de organizaciones como ACIERA y reconfiguró a las antiguas "sectas" como aliados. Simétricamente, tambien las minorías movilizadas por nuevos derechos valorizaron la trayectoria y la palabra pública de la disidencia evangélica no conservadora. La dirigencia política y los medios de comunicación, asimismo, contabilizaron a los distintos actores evangélicos como participantes legítimos y calificados en los debates mencionados. En definitiva, la discusión en torno al matrimonio igualitario escenificó, más allá de su desenlace, el nuevo estatus político de los evangélicos en Argentina.

Este primer reconocimiento se complementa con una ulterior valorización, que a su tiempo se vincula con el trabajo social que las diferentes iglesias realizan habitualmente como prolongación natural de su actividad pastoral. Merenderos, comedores, talleres para la violencia de género, grupos de asistencia a las adicciones y bolsas de trabajo (entre otras actividades) forman parte de un repertorio histórico de intervención de grupos evangélicos en la trama cotidiana de los barrios populares de Argentina (Míguez 1998; Semán 2006). Su constancia y eficiencia en el despliegue de estas actividades permitió, en primer término, que fueran incorporadas a la red de solución de problemas que los habitantes de dichos barrios construyen cuando su situación socioeconómica y afectiva se fragiliza. Más tarde, esta expertice evangélica fue incluida en el campo de las políticas públicas, porque los decisores políticos valoraron la gravitación de esas acciones religiosas en los territorios más vulnerables. Mencionábamos arriba la inclusión de las federaciones evangélicas en la Mesa de Diálogo Social que se gestó bajo la situación crítica que atravesó la Argentina en los años 2001-2002. El trabajo de Carbonelli (2015b) destaca que dicha inclusión no resultó un acto momentáneo, sino que se estabilizó y se prolongó en una pluralidad de intervenciones en el campo de las políticas públicas, preferentemente a escala municipal y provincial, donde los evangélicos se transformaron en detectores de demandas sociales y canalizadores de los recursos del Estado. De forma reciente, el estudio de Jones y Cunial (2016) muestra cómo la intersección entre lo político y lo evangélico en el campo de las políticas públicas excede el espacio de la asistencia social y se prolonga, también, hacia el abordaje del consumo problemático de drogas, un área en la que la presencia evangélica fue pionera.

Finalmente, el análisis desplegado en estas líneas abreva, en una tercera tesis o conclusión, que, en sus pretensiones y alcances, se direcciona al plano más general de la reconfiguración de las relaciones político-religiosas en la Argentina democrática. Apelamos al concepto de reconfiguración porque, a nuestro juicio, las controversias permiten entrever discontinuidades en la matriz político-religiosa imperante en el país hasta la recuperación democrática. 
El primer cambio resulta en el ensanchamiento del espacio público: las movilizaciones evangélicas que hemos citado resultan la muestra palmaria de una presencia religiosa más plural y sostenida que la conocida previamente, en la cual la hegemonía católica y sus contactos políticos eclipsaba la politización de la disidencia. El segundo efecto remite a una modulación en el discurso y en las estrategias: tanto los viejos como los nuevos participantes religiosos en la arena política tuvieron que adecuar sus intervenciones a las exigencias del juego democrático. La apelación a lo sagrado por sí sola no bastó para influir en la conducta de los decisores políticos, y por ello, instituciones, como el Episcopado Católico o ACIERA, recurrieron a una combinación de argumentos jurídicos y científicos y a las alusiones sobre la existencia de una mayoría moral para convencer y movilizar a la opinión pública e imponer sus intereses y cosmovisiones en el debate legislativo.

Tales modificaciones no deben nublar el hecho de que la recuperación y la consolidación democrática no significó la desaparición de la palabra religiosa en el ciclo de movilizaciones en el espacio público. Por el contrario, el hecho religioso se mostró potente y productivo al aportar actores, estrategias y argumentos a esos debates. Por consiguiente, su presencia desnuda que, en tanto proceso transversal, la democratización de la sociedad argentina no necesariamente se vincula a una laicización de las relaciones sociales que la componen (Esquivel 2015).

Las tesis presentadas representan, en su articulación, una mirada situada sobre las relaciones político-religiosas en Argentina en un contexto histórico determinado. Por su carácter coyuntural, no deben tomarse como aserciones definitivas, sino más bien como hipótesis de trabajo por retomar en futuras investigaciones, orientadas al análisis de las dinámicas y nuevas controversias que involucran a actores políticos y religiosos en la segunda década del milenio.

\section{Bibliografía}

Aboy Carlés, Gerardo. 2001. Las dos fronteras de la democracia argentina. La reformulación de las identidades políticas de Alfonsín a Menem. Rosario: Homo Sapiens Ediciones, 2001.

Algranti, Joaquín. 2010. Política y Religión en los márgenes. Nuevas formas de participación social de las mega-iglesias evangélicas en la Argentina. Buenos Aires: Ediciones Ciccus, 2010.

Auyero, Javier. 2001. La política de los pobres. Las prácticas clientelistas del peronismo. Buenos Aires: Manantial, 2001.

Becker, Howard. 2010. Outsiders. Hacia una sociología de la desviación. Buenos Aires. Siglo XXI, 2010. 
Bianchi, Susana. 2004. Historia de las religiones en Argentina. Las minorías religiosas. Buenos Aires: Sudamericana, 2004.

Caimari, Lila. 1995. Perón y la Iglesia Católica. Religión, Estado y Sociedad en la Argentina (1943-1955). Buenos Aires: Ariel, 1995.

Campos Machado, María das Dores. 2006. Política e Religião. A participação dos evangélicos nas eleicoes. Río de Janeiro: Editora FVG, 2006.

Carbonelli, Marcos Andrés y Mariela Mosqueira. 2008. «Luis Palau en Argentina: construcción mediática del cuerpo evangélico, disputa por el espacio público y nuevas formas de territorialidad». Enfoques 20(2): 6587.

Carbonelli Marcos, Karina Felitti y Mariela Mosqueira. 2011. «Religión, sexualidad y política en la Argentina: intervenciones católicas y evangélicas entorno al aborto y el matrimonio igualitario». Revista del Centro de Investigación 9(36): 25-43.

Carbonelli Marcos y Mariela Mosqueira. 2012. «Evangélicos y política: tensiones en torno a la libertad e igualdad religiosa en Argentina». Revista Científica Guillermo de Ockham 10(1): 41-55.

Carbonelli, Marcos. 2015a. «Pan y Palabras. La inserción evangélica en la gestión pública en Argentina». Religião e Sociedade 35(2): 73-95.

Carbonelli, Marcos. 2015b. «Valores para mi País. Evangélicos en la esfera política argentina 2008-2011». DADOS- Revista de Ciências Sociais 58(4): 981-1015.

Carbonelli, Marcos. 2016. «Los evangélicos y la arena partidaria en la Argentina contemporánea». Estudios Políticos 37: 193-219.

Carbonelli, Marcos y Daniel Jones. 2015. «Igualdad religiosa y reconocimiento estatal: instituciones y líderes evangélicos en los debates sobre la regulación de las actividades religiosas en Argentina (2002-2010)». Revista Mexicana de Ciencias Políticas y Sociales LX (225): 139-168.

Catoggio, María Soledad. 2008. «Gestión y regulación de la diversidad religiosa. Políticas de "reconocimiento" estatal: el Registro Nacional de Cultos». En Religión y Política. Perspectivas América Latina-Europa editado por Fortunato Mallimaci, 105-116. Buenos Aires: Biblos.

Cefaï, Daniel. 2002. «Qu'est-ce qu'une arène publique? Quelques pistes pour une approche pragmatiste». En L'Héritage du pragmatisme. Conflits d'urbanité et épreuves de civisme dirigido por Daniel Cefaï y I. Joseph, 76-102. Paris: La Tour d'Aigues- Editions de l'Aube.

De Risio, Mónica. 2018. «Ley del Divorcio Vincular (1987) y Ley del Matrimonio Igualitario (2010). Actores evangélicos y Estado en el período democrático reciente». En Sexo, drogas y religión. Debates y políticas públicas sobre drogas y sexualidad en la Argentina democrática, dirigido por Daniel Jones, 59-110. Buenos Aires: Teseo. 
Di Stefano, Roberto y Zanatta, Loris. 2000. Historia de la Iglesia Argentina. Desde la conquista hasta fines del siglo XX. Buenos Aires: Mondadori, 2000.

Esquivel, Juan Cruz. 2004. Detrás de los muros. La Iglesia Católica en tiempos de Alfonsín y Menem (1983-1999). Bernal, Buenos Aires: Universidad Nacional de Quilmes Editorial, 2004.

Esquivel, Juan Cruz. 2015. «Religión y política: la influencia religiosa sobre las definiciones parlamentarias en materia de derechos sexuales y reproductivos». En Permeabilidades activas. Religión, política y sexualidad en la Argentina democrática, dirigido por Juan Cruz Esquivel y Juan Marco Vaggione. Buenos Aires: Biblos.

Freston, Paul. 2001. Evangelicals, and politics in Asia, Africa and Latin America. New York: Cambridge University Press, 2001.

Frigerio, Alejandro e Hilario Wynarczyk. 2008. «Diversidad no es lo mismo que pluralismo: cambios en el campo religioso argentino (1985-2000) y lucha de los evangélicos por sus derechos religiosos». Sociedade $e$ Estado 2(3): 227-260.

Hiller, Renata. 2011. «Conyugalidad y ciudadanía: disputas en torno a la regulación estatal de las parejas gay lésbicas en la Argentina contemporánea». Tesis doctoral. Universidad de Buenos Aires.

Jones, Daniel; Ana Laura Azparren y Luciana Polischuk. 2010. «Evangélicos, sexualidad y política: las instituciones evangélicas en los debates públicos sobre Unión Civil y Educación Sexual en la Ciudad Autónoma de Buenos Aires (2003-2004)». En El activismo religioso conservador en Latinoamérica, compilado por Juan Marco Vaggione, 193-248. Ferreyra Editor: Córdoba.

Jones, Daniel y Marcos Carbonelli. 2012. «Evangélicos y derechos sexuales y reproductivos: actores y lógicas políticas en la Argentina contemporánea». Ciências Sociais Unisinos 48(3): 225-234.

Jones Daniel y Santiago Cunial. 2012. «Derrota parlamentaria y reposicionamiento político de actores religiosos: el rechazo de la federación Alianza Cristiana de Iglesias Evangélicas de la República Argentina (ACIERA) a la ley de matrimonio igualitario». Sociedad $y$ Religión 22(37): 85-122.

Jones Daniel, Santiago Cunial y Ana Lía Quintáns. 2014. «De la resistencia a la militancia: las iglesias evangélicas en la defensa de los derechos humanos (1976-1983) y el apoyo al matrimonio igualitario (2010) en Argentina». Espiral: Estudios sobre Estado y Sociedad 21: 109-142.

Jones, Daniel y Santiago Cunial. 2016. «Más allá de los límites del Estado. Instituciones católicas y evangélicas de partidos del Gran Buenos Aires (Argentina) en la implementación de políticas públicas sobre drogas». Desafíos 29(2): 85-123. 
Mallimaci, Fortunato. 2015. El mito de la Argentina Laica. Catolicismo, política y Estado. Buenos Aires: Capital Intelectual, 2015.

Marostica, Matt. 1994. «La Iglesia Evangélica en la Argentina como Nuevo Movimiento Social». Sociedad y Religión 12: 3-21.

Marostica, Matt. 1997. Pentecostal and politics; the creation of the Evangelical Christian Movement in Argentina, 1983-1993. Tesis doctoral. University of California.

Marostica, Matt. 2000. «La Nueva Política Evangélica: el movimiento evangélico y el complot católico en la Argentina». Ciencias Sociales y Religión 2: 11-30.

Merklen, Denis. 2005. Pobres ciudadanos: las clases populares en la era democrática, Argentina, 1983-2003. Buenos Aires: Gorla, 2005.

Míguez, Daniel. 1998. «Política y Magia en un suburbio de Buenos Aires: estrategias indirectas de expresión demandas en un contexto de clientelismo político». Sociedad y Religión 16: 75-94.

Seiguer, Paula. 2015. «Laicidad y pluralidad religiosa temprana. Los metodistas y el Estado laico en la década de 1880». Revista Quinto Sol 19: 1-22.

Semán, Pablo. 2000. «El Pentecostalismo y la religiosidad de los sectores populares». En Desde Abajo. La transformación de las identidades sociales compilado por Maristella Svampa, 155-180. Buenos Aires: Biblos-Universidad Nacional General Sarmiento.

Semán, Pablo. 2006. Bajo continuo. Exploraciones descentradas sobre cultura popular y masiva. Buenos Aires: Gorla, 2006.

Semán, Pablo. 2013. «Pentecostalismo, política, elecciones y poder social». Cultura y Religión 7: 60-81

Silveira Campos, Leonildo. 2005. «De "políticos evangélicos" a "políticos de Cristo": la trayectoria de las acciones y mentalidad política de los evangélicos brasileños en el paso del siglo XX al siglo XXI». Ciencias Sociales y Religión 7: 157-186.

Vaggione, Juan Marco. 2005. «Los roles políticos de la religión. Género y Sexualidad más allá del Secularismo». En Nombre de la Vida compilado por Marta Vasallo. Córdoba: CDD.

Vaggione, Juan Marco y Daniel Jones. 2015. «La política sexual y las creencias religiosas: el debate por el matrimonio para las parejas del mismo sexo (Argentina, 2010)». Revista de Estudios Sociales 51: 105117.

Wynarczyk Hilario, Semán Pablo y de Majo Mercedes. 1995. Panorama actual del campo evangélico en la Argentina. Un estudio sociológico. Buenos Aires: Facultad Internacional de Educación Teológica, 1995. 
Wynarczyk, Hilario. 2006. «Partidos políticos conservadores bíblicos en la Argentina. Formación y ocaso 1991-2001». Civitas-Revista de Ciências Sociais 2: 11-41.

Wynarczyk, Hilario. 2009. Ciudadanos de dos mundos. El Movimiento evangélico en la vida pública argentina 1980-2001. San Martín: UNSAM EDITA de Universidad Nacional de San Martín.

Wynarczyk, Hilario. 2010. Sal y luz a las naciones. Evangélicos y política en la Argentina (1980-2001). Buenos Aires: Siglo XXI

Wynarczyk, Hilario y Ari Pedro Oro. 2012. «El Pentecostalismo en América Latina». Religioni e Società xxvii (73): 24-31. 